\title{
A lei de Mitscherlich aplicada a experimentos de adubação com vinhaça
}

FREDERICO PIMENTEL GOMES

E. S. A. "Luiz de Queiroz" U. S. P. - Piracicaba

\section{INDICE}

$\begin{array}{lllllllll}1-\text { Introdução } & \ldots & \ldots & \ldots & \ldots & \ldots & \ldots & \ldots & \ldots\end{array}$

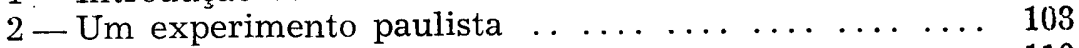

3 - Um experimento pernambucano $\ldots \ldots \ldots \ldots \ldots$

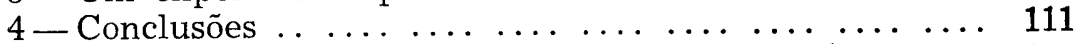

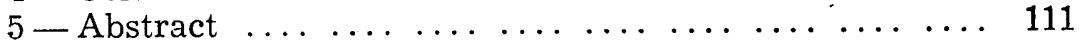

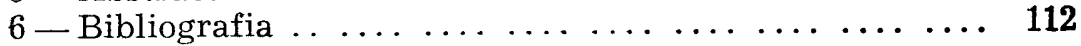




\section{INTRODUÇÃO}

A adubação da cana-de-açúcar com vinhaça (também cha mada restilo ou calda de usina) é técnica nova e que, por isto mesmo, apresenta aspectos ainda mal conhecidos ou até intei.ramente incógnitos. Por isto é de interêsse discutir, como fazemos a seguir, pela primeira vez na literatura, a aplicação dia lei de Mitscherlich a dois experimentos de adubação com vinhaça, um em S. Paulo, outro em Pernambuco. Os resultados obtidos são bem precisos e mostram as vantagens dêste método de análise em comparação com os processos grosseiros de tisu mais geral.

\section{UM EXPERIMENTO PAULISTA}

Os dados que estudaremos foram publicados por ARRUDA e se referem a um experimento por êle realizado em terra vermelha (falsa roxa) esgotada, ácida ( $\mathrm{pH}$ 5,5) da Estação Experimental de Cana de Piracicaba (SP).

Além da vinhaça, em doses diversas, usou-se em alguns tratamentos adubação mineral com NPK, nas doses respectiva. de $45-120-45 \mathrm{~kg} / \mathrm{ha}$. As médias de produção de cana no primeiro corte são dadas a seguir.

\section{Produção de cana em t/ha}

\section{Sem N P K}

Sern vinhaça

$\measuredangle \mathrm{m} 250 \mathrm{~m}^{3} /$ ha de vinhaça

Com $500 \mathrm{~m}^{3} /$ ha de vinhaça

Com $1000 \mathrm{~m}^{3} /$ ha de vinhaça
47,0

75,0

90,0

98,0
Com N P K

76,0

112,0

112,0

107,0

Os dados referentes à aplicação da vinhaça com $\mathrm{N} \mathrm{P} \mathrm{K} \mathrm{ıào}$ se prestam ao uso da lei de Mitscherlich: as doses de restilo são, aparentemente, tão elevadas que a menor delas já dá a produção máxima possível. Já na ausência de N P K tal rãa acontece e a lei de Mitscherlich se mostra conveniente e indicada. A equação nbtida é:

$$
\mathrm{y}=100,8[1-10-0,00132(\mathrm{x}+206)] \quad,
$$


onde $x$ está expresso em $\mathrm{m}^{3} /$ ha de vinhaça. O coeficiente $\mathrm{dc}$ eficácia para o restilo é, pois, c $=0,00132$.

Os aumentos sucessivos de produção de cana, para doses consecutivas de $50 \mathrm{~m}^{3} /$ ha de vinhaça são as seguintes, em t/ha.

\begin{tabular}{cccccccccccr} 
1a. & 2 a. & 3a. & 4 a. & 5a. & 6a. 7 a. & 8a. & 9 a. & 10a. & 11a. $12 \mathrm{a}$. \\
\hline 7,6 & 6,5 & 5,6 & 4,7 & 4,3 & 3,5 & 3,1 & 2,6 & 2,2 & 1,9 & $.1,7$ & 1,4
\end{tabular}

Verifica-se logo que os novos acréscimos de produção caem ràpidamente. Estimado em $\mathrm{Cr} \$ 20,00$ por metro cúbico o custo de transporte da vinhaça (no caso do uso de caminhóes-tanque), como faz ARRUDA, e tomada a Cr\$250,00 a tonelada de cana, no campo e sem cortar, verifica-se logo que cada dose de restilo, de 50 metros cúbicos, custa $\mathrm{Cr} \$ 1.000,00$. Ora, a quinta dose de vinhaça nos dá em retribuição $4,3 \times 250=1.175,00$ crızeiros e ainda é, portanto, compensadora, mas as seguintes já não satisfazem do ponto de vista econômico. Concluir-se-ja, pois, que a dose mais conveniente, sob êste ponto de vista, serià de cêrca de $250 \mathrm{~m}^{3} /$ ha de restilo. Resultado mais exato, mas menos intuitivo, se obteria pela fórmula seguinte (inédita) :

$$
x^{*}=117,2+\frac{1}{0,00132} \log \frac{w u}{250 t},
$$

na qual $x^{*}$ é a dose de vinhaça a usar, $w$ é o preço da tonelada de cana (de pé e no campo), $t$ é o custo de transporte e aplicação de cada metro cúbico de vinhaça, e $u$ é o aumento de produção de cana correspondente à dose (tomada como padrão) de $250 \mathrm{~m}^{3} /$ ha de restilo.

No caso presente o aumento de produção $u$ observado, referente à dose padrão, é de 28,0 t/ha. Mas o cálculo, baseado na curva adaptada a todos os dados, indica como melhor estimativa $u=28,7 \mathrm{t} / \mathrm{ha}$. Com êsses valores de $u$ obtemos, respectivamente, $x^{*}=228 \mathrm{~m}^{3} /$ ha e $x^{*}=236 \mathrm{~m}^{3} /$ ha. A dose de cêrca de $230 \mathrm{~m}^{3} /$ ha de vinhaça parece, pois, a mais indicada, se aceitarmos êsses preços.

E' claro que se o custo do transporte do restilo baixar, como deverá acontecer se forem utilizadas bombas e canalizações, então valerá a pena empregar quantidades maiores de ${ }_{1}$ nhaça por hectare.

No caso da adubação mineral concomitante, provàvelmente a dose de $230 \mathrm{~m}^{3} /$ ha já seria excessiva, mas os dados não permitem conclusões mais precisas a êsse respeito. 


\section{UM EXPERIMENTO PERNAMBUCANO}

Os dados que vamos discutir provêm de um interessantíssimo experimento fatorial com $\mathrm{N}, \mathrm{P}, \mathrm{K}$ e vinhaça, realizado em solo arenoso de tabuleiro na região Norte do litoral de Pernambuco, por Abelardo Costa e Cláudio de Britto Pereira. As produções médias de cana-planta obtidas, para as diversas doses de vinhaça, são dadas a seguir.

Sem vinhaça

Com $250 \mathrm{~m}^{3} / \mathrm{ha}$ de vinhaça

$41,0 \mathrm{t} / \mathrm{ha}$

Com $500 \mathrm{~m}^{3} /$ ha de vinhaça

$108,3 \mathrm{t} / \mathrm{ha}$

$134,3 \mathrm{t} / \mathrm{ha}$

Como se vê, o efeito da calda de usina foi airıda mais evidente do que no experimento paulista. A equação de Mitscherlich obtida foi:

$$
\mathrm{y}=150,7[1-10-0,00165(\mathrm{x}+84)] .
$$

Também aqui $x$ está expresso em $\mathrm{m}^{3} / \mathrm{ha}$. O valor de $\mathrm{c}=0,00165$ concorda bem com o achado em S. Paulo $(0,00132)$.

Os aumentos sucessivos de produção de cana para doses consecutivas de $50 \mathrm{~m}^{3} /$ ha de restilo são dadas a seguir, em t/ha.

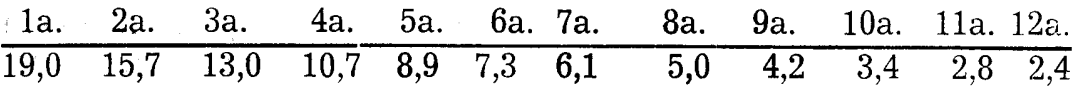

Em condições análogas às adotadas em S. Paulo, valeria a pena ir até a $9 \mathrm{a}$. dose, isto é, aplicar cêrca de $450 \mathrm{~m}^{3} / \mathrm{ha}$ de calda de usina.

Um cálculo mais preciso seria dado pela fórmula:

$$
\mathrm{x}^{*}=115,2+\frac{1}{0,00165} \log \frac{\mathrm{w} \mathrm{u}}{250 \mathrm{t}} .
$$

Note-se que esta fórmula difere muito pouco da que obtivemos com dados paulistas.

Como no caso presente temos $u=67,3$ t/ha, calcula-se $\mathrm{x}^{*}=434 \mathrm{~m}^{3} /$ ha , o que pràticamente coincide com o resultado já obtido de maneira mais grosseira. Seria econômicamente compensador, pois, aplicar ao solo, nas condições do experimento, cêrca de $430 \mathrm{~m}^{3} /$ ha de vinhaça. 


\section{CONCLUSÕES}

Os resultados acima expostos mostram que os experimentos com vinhaça, como outros ensaios de adubação, podem ser estudados, com proveito, com o auxílio da lei de Mitscherlich. Não obstante as diferenças de clima e solo, há certas normas comuns a todos os experimentos com fertilizantes. Faz-se mister aproveitá-las, para interpretação mais precisa e racional dos ensaios de adubação. $\mathrm{E}$ isto se consegue, como mostramos acima, pelo uso racional da lei de Mitscherlich, nos moldes, hoje em uso no Brasil e na Inglaterra; expostos em vários trabalhos mais modernos sôbre o assunto.

\section{ABSTRACT}

The author studies, with the aid of Mitscherlich's law, two experiments of sugar cane fertilization with vinasse. The first one, carried out in Piracicaba, State of S. Paulo, by ARRUDA, gave the following yields.

No vinasse

$250 \mathrm{c.m} . / \mathrm{ha}$. of vinasse

500 do.

1000 do.
47.0 tens/ha.

75.0 do.

90.0 do.

98.0 do.
76.0 tons/ha.

112.0 do.

112.0 do.

107.0 do.

Data without NPK were appropriate for the fitting of the law, the equation of which was found to be:

$$
\mathrm{y}=100.8\left[1-10^{-0.00132(\mathrm{x}+206)}\right] \quad
$$

where $y$ is measured in metric tons/hectare, and $x$ in cubic meters/hectare.

The optimum amount of vinasse to be used is given by the formula

$$
\mathrm{x}^{*}=117.2+\frac{1}{0.00132} \log \frac{\mathrm{w} \mathrm{u}}{250 \mathrm{t}}
$$


being $u$ the response to the standard dressing of 250 cubic meters/hectare of vinasse, $w$ the price per ton of sugar cane, and $t$ the price per cubic meter for the transportation of vinasse.

In Pernambuco, a $3^{4} \mathrm{NPK}$ vinasse experiment gave the following mean yields:

No vinasse

250 c.m./ha. of vinasse

500 do.
41.0 tons/hectare

108.3 do.

134.3 do.

The equation obtained was now

$$
\mathrm{y}=150.7[1-10-0.00165(\mathrm{x}+84)],
$$

being the most profitable level of vinasse

$$
\mathrm{x}^{*}=115.2+\frac{1}{0,00165} \log \frac{\mathrm{w} \mathrm{u}}{250 \mathrm{t}}
$$

One should notice the close agreement of the coefficients $c(0.00132$ in S. Paulo and 0.00165 in Pernambuco).

Given the prices of Cr $\$ 20.00$ per cubic meter for the transportation of vinasse (in trucks) and Cr\$250.00 per ton of sugar cane (uncut, in the fields) the most profitable dressings are: $236 \mathrm{c.m} . / \mathrm{ha}$. of vinasse in S. Paulo, and $434 \mathrm{c.m} . / \mathrm{ha}$. in Pernambuco.

\section{BIBLIOGRAFIA}

1. ARRUDA, Homero Corrêa, 1956 - Variedades de Cana Adubação Racional e Aplicação Econômica da Vinhaça (mimeografado). 10 pp. Piracicaba.

2. HODNETT, G. E., 1956 - The Responses of Sugar-cane to Fertilizers Empire J. Exp. Agric. 24: 1-19.

3. MITSCHERLICH, E. A., 1954 - Bodenkunde, Paul Parey, Berlim.

4. PIMENTEL GOMES, F., 1953 - The Use of Mitscherlich's Regression Law in the Analysis of Experiments with Fertilizes. Biometrics 9: 498-516. 